\title{
Application of VISSIM software in traffic engineering course reform of road and bridge major
}

\author{
Bojun Yang \\ Nanyang Institute of Technology, Nanyang 473004, China \\ ybojun@163.com
}

Keywords: VISSIM software; course reform; Traffic Engineering.

\begin{abstract}
Traffic engineering course is a compulsory course of road and bridge major. It is related to road and bridge major. In the paper, the method of applying VISSIM software in traffic engineering classroom teaching is described. Students' theoretical knowledge learning ability and practice ability are improved through the mode reform.
\end{abstract}

\section{Introduction}

Traffic engineering is a young subject derived from road engineering. It has the purpose of seeking a traffic system planning, construction and management solution with the maximum travel efficiency, least traffic accidents, fastest traffic speed, minimum transportation cost, minimal environmental impact and lowest energy consumption, thereby reaching safe, rapid, economic, convenient, comfortable, energy-saving and low environmental pollution purposes. Traffic engineering design plan evaluation is more convenient and effective due to traffic flow theory and development of computer technology. VISSIM software, as an important tool of modern microscopic traffic flow theory application, plays an important role in traffic engineering theory application. The software is introduced in traffic engineering course for teaching. Students can contact more cutting-edge knowledge of traffic engineering. The understanding on traffic engineering disciplines and theoretical knowledge is deepened through the application of VISSIM software.

\section{Problems in traffic engineering teaching}

Theory teaching is mainly adopted in traffic engineering course. Basic concept and important theory of traffic engineering are mainly described in the course. Theory is emphasized, and practice is ignored in course teaching. Students generally feel boring and very abstract, it is difficult to master knowledge points, and students can not actually understand the traffic engineering major as well as its relationship with road and bridge major, which violate the original intention of the course.

\section{Application of VISSIM software in Traffic Engineering course}

\subsection{Application method of VISSIM software in classroom teaching}

The VISSIM software and its significance in academic frontiers are introduced in the first classroom of the course firstly. Secondly, task assignment is arranged in three stages of the subsequent course respectively. Stage I: the simulation software is studied seriously, and students are capable of simple simulation. Stage II: the arranged task is seriously analyzed and studied for comprehending the pre-simulation object. Stage III: the task is simulated, evaluation data is obtained, and the optimum plan can be obtained finally. In the last course, defense session. One VISSIM simulation report is completed after class.

Because 48 students participate in the course, a total of 12 groups are set this time, including four students in each group. 


\subsection{Comprehension of traffic simulation software VISSIM through the course reform}

Traffic simulation software belongs to a new contact object for students. Students can learn the origin, function, composition and operation method of the software through the introduction of the software in the classroom, and participate in field practice through practice.

\subsection{Deepening understanding on the intersection design process with signal through simulation}

Signal intersection control is an important content in traffic engineering course traffic management and control chapter. In theoretical study, the flow chart of signal intersection design is complex, students can not actually understand easily by description only. The course reform has the task of traffic simulation on one signal intersection. The plan is evaluated through simulation output index. The signal intersection plan is simulated through the VISSIM software, teachers further combine the design flow chart for explanation, thereby deepening the understanding on the design process theory of signal intersection.

\subsection{Deepening of understanding on signal control basic concepts through simulation}

It is necessary to set VISSIM software, and draw a road network diagram in the process of simulation with VISSIM software. Therefore some most basic parameters should be set. The understanding on intersection channelizing plan, signal cycle, phase, flow rate, flow velocity, vehicle composition, density, car-following theory, traffic capacity, service level and other basic concepts can be deepened through setting these basic parameters and road network.

\subsection{Deepening of understanding on the important evaluation indexes of traffic engineering through simulation}

Each group utilizes VISSIM software to evaluate the given task. Plan evaluation indexes are obtained through operation analysis, such as delay value, travel time, queue length, etc. Students can understand the basic concept, function and significance of these basic evaluation indexes in the application process of the software.

\section{Effect of the course reform and future improvement measure}

It is discovered that the students' learning initiative and enthusiasm have been greatly improved through reform and practice of the whole process. For example, some group can actively consult relevant information from the network and library for studying, some groups can seriously discuss and analyze, some students hope to give optimal and positive suggestions to tasks subsequently after the course is ended. It can be concluded that the software application has attracted the interest of the students to study actively with positive effect. However, some problems are also discovered. For example, four members in some groups do not cooperate actively, who shuffle mutually, thereby resulting in poor simulation effect. The learning enthusiasm of some students is also lowered, the work division is not clear in some group, the task arrangement is more difficult in some group, and the task is easier in some group, etc. Next, efforts should be made in the aspect of group division and task assignment. Some tasks with equal difficulty are arranged, groups are divided rationally, and unclear group member division and mutual shuffle should be avoided.

\section{Function of VISSIM software application in traffic Engineering course reform}

\subsection{Change of traditional teaching mode}

Traditional 'teaching model' teaching mode is changed in traffic engineering course after introduction of classroom practice teaching link. Role conversion of 'teacher guidance and student orientation' is realized. Basic concept and design method of traffic engineering are mastered through practical training. Students actively participate in design and learning of traffic engineering theory knowledge application, thereby improving students' learning initiative.

\subsection{Improvement of students' practical ability}

The students actively consult materials through course practice, who are involved in the problem analysis, software production and system modification. Students display own practical achievements through report in the course practice link on the final classroom. PPT is made, and students prepare 
carefully. Some students also prepare lecture notes. Students are exercised through these links, and their practice ability is also improved.

\subsection{Promotion of evaluation mode reform}

The method of theoretical examination is adopted as a more common appraisal mode. Centesimal system mode is always adopted, wherein examination accounts for $80 \%$, usual performance accounts for $20 \%$. Since classroom practice link is introduced in the course, the course evaluation mode is also changed, and the evaluation score proportion is changed into follows: software production score accounts for $40 \%$, defense performance score accounts for $20 \%$, simulation analysis report accounts for $20 \%$, and usual performance accounts for $20 \%$. Theoretical understanding, software production capacity, PPT and word application ability, design and display ability as well as usual performance are evaluated comprehensively.

\section{Conclusion}

VISSIM software is an auxiliary tool. Simulation software is introduced in the traffic engineering course. It can play certain promotion role in teaching reform of the course. Students' learning interests can be improved through realistic simulation environment, thereby improving the learning initiative and participation, and being closer to the objective of cultivating applied talents.

\section{References}

[1]. Zhou Hui. Teaching reform and practice of 'warehousing and distribution management'. Cooperation Economy and Technology, 2012 (10): 126-127.

[2]. Zeng Zhen. Application of 3D logistics simulation training teaching in logistics teaching of of secondary vocational school. Time Finance, 2013 (8): 182-186.

[3]. Wang Kai, Liu Mei, Zeng Xianqiao. Simulation design of single-chip microcomputer control system based on Proteus. Electronic Design Engineering, 2015, 23 (8):180-184.

[4]. Gao Yanfen, Cai Heng. Discussion on single-chip microcomputer experimental teaching based on combination of Proteus simulation and experimental board. Education Teaching Forum, 2015 (23): 138-139.

[5]. Liu Wenguang, Zhang Mingming. Application of Proteus simulation in the single-chip microcomputer course project teaching. Information Technology and Informatization, 2012 (2).

[6]. Wang Kai. Reform and practice of course teaching of 'engineering cost software and application' Industry and Technology Forum, 2016,15(10):181-182. 